\title{
'ADDITIVE' AND 'SUBTRACTIVE': CHALLENGES IN EDUCATION FOR MULTILINGUALISM
}

Peter Plüddemann

This article provides a critique of the use of the terms 'additive bilingualism' and 'subtractive bilingualism', arguing that the use of these terms has led to confusion. The article suggests caution in equating language learning outcomes with particular programmes or types or models without regard to the contexts in which they are implemented. It argues for closedefinition of terms, but warns that this alone will not effect change in language-in-education policies. Promotion of multilingualism will require the systematic elaboration, standardisation and use of African language as languages of learning and teaching.

Hierdie artikel lewer kritiek op die gebruik van die terme toegevoegde tweetaligheid en wegnemende tweetaligheid, deur te argumenteer dat die benutting van die terme gelei het tot verwarring. Die artikel stel voor dat versigtigheid aan die dag gelê moet word om nie taalaanleeruitkomste gelyk te stel aan spesifieke programme of tipes modelle sonder inagneming van die konteks waarbinne hulle geïmplementeer word nie. Dit argumenteer ten gunste van geslote definisies van terme, maar waarsku dat sodanige definiëring nie eiehandig verandering teweeg sal bring in taal-in-onderwys-beleidsrigtings nie. Die bevordering van meertaligheid sal die sistematiese uitbreiding, standaardisering en gebruik van Afrikatale as tale waarin onderrig ontvang en gelewer word, verg.

\section{INTRODUCTION}

As of 14 July 1997 'additive multilingualism' has become an official language-in-education approach for public schools in South Africa. The national Ministry of Education commits itself to a paradigm which, amongst other features,

- recognises cultural diversity as a national asset, and sees the need to promote multilingualism and develop the 11 official languages

- endorses an additive approach to bilingualism

- gives individuals (in practice, parents/guardians) the right to choose the language of learning and teaching (LOLT) (DoE 1997:2-3).

The paradigm represents a radical break from its apartheid predecessors in every respect. Undergirding it are a number of terms or keywords that encode theories which derive orginally from North American and European research into bilingual education but which have been newly contextualised by South African educators and language planners. 'Additive bilingualism' and 'subtractive bilingualism' constitute two such keywords with established 
meanings and a long history in bilingual education research. 'Additive multilingualism', on the other hand, is a recent South African neologism.

This article traces the use in South Africa of these (earlier) constructs in historical perspective, before problematising 'additive multilingualism' in terms of its present deployment and degree of usefulness ${ }^{1}$. My main argument will be that while the coinage of 'additive multilingualism' is historically explicable, its current uses have caused confusion due to the wide range of permissible interpretations. This confusion, in turn, may contribute to the dilution of the challenge to schools to change their language policies and practices in accordance with the goal of promoting multilingualism. The article ends by suggesting a return to other, older concepts with well-established meanings. Underlying the concern with terminology is the belief that the concepts we use contribute towards the setting up of a paradigm or world-view. The concepts we choose, and the meanings we give them can and often do become self-fulfilling prophecies. The word on its own cannot change the world; yet the world cannot be changed without the word.

\section{NORTHERN COINAGES}

\section{Liddicoat points out that W E Lambert's research on bilingualism in Canada}

drew attention to the close association between bilingualism and the social psychological mechanisms involved in language behaviour. In particular, the relative social status of each of the bilingual person's languages and the person's perception of the difference in status has an important function in the development of bilingualism. (1991:6)

For Lambert, 'additive bilingualism' refers to a situation in which 'the addition of a second language and culture are unlikely to replace or displace the first language and culture (in Baker 1993:57). It is the 'process of developing bilingual and bicultural skills' in children who, 'with no fear of ethnic/linguistic erosion, can add one or more foreign languages to their accumulating skills, and profit immensely from the experience, cognitively, socially and even economically' (1983:99-100). Liddicoat sums this up succinctly: 'Additive bilingualism develops when both languages and the culture associated with them bring complementary positive elements to the child's overall development' (1991:6). Conversely, for Lambert, subtractive bilingualism is characterised by the loss or erosion of a home or first language and culture (1980, in Baker 1993:57). In the North American and European contexts, this typically happens when a minority language learner 'enters a school where a high prestige, socially powerful, dominant language like English is introduced as the exclusive language of instruction', resulting in 'a steam-roller effect of the powerful dominant language [that] can make foreign home languages and cultures seem homely in contrast, ghosts in the closet to be eradicated and suppressed' (Lambert 1983:100). In other words, '[s]ubtractive bilingualism... develops when the two languages are competing rather than complementary' (Liddicoat 1991:6).

This article draws substantially on my 1996 MPhil mini-dissertation, 'Response to Multilingualism:

Language Support in a Western Cape Primary School'. 
Lambert's definition arose in the light of the success of French-immersion programmes for English-speaking (language majority) children from 'literate' homes in the Francophone Canadian province of Quebec from the mid-1960s onwards. Success related to individuals' bilingual proficiency, security of cultural identity, and positive language attitudes (Tosi 1990:104). These positive outcomes ('additive bilingualism') contrasted sharply with the failure of target-language (i.e. English) immersion programmes for language minority children in Sweden and the USA ('subtractive bilingualism'). However, as subsequent studies have shown (Ramirez 1991; Thomas \& Collier 1997), bilingual programmes for language minority children in which the home (primary) language features strongly have a far higher success rate. For in such 'high degree of success contexts the linguistic goal has been bilingualism, and the societal goal has been a positive one' (Skutnabb-Kangas 1988:27). The psychological theory of Jim Cummins provided one answer as to why immersion programmes succeeded for majority language children but not for minority language children. Tosi sums it up usefully:

Cummins' threshold hypothesis (1979) addressed directly the question of interdependence between L1 and L2 in bilingual education and attempted to provide an academically consistent explanation of its contradictory findings. He hypothesised that there may be a threshold level of linguistic proficiency bilingual children must attain in their $\mathrm{L} 1$ before they can benefit from the home-school language switch and from instruction in L2. (1990:106)

\section{3. 'ADDITIVE' AND 'SUBTRACTIVE BILINGUALISM' IN SOUTH AFRICA}

On the basis of these North American and European constructs and in conjunction with an understanding of concepts such as linguicism (Phillipson 1988), 'additive' and 'subtractive bilingualism' have helped socialist and democratically-aligned language workers and educationists in South Africa mount a sustained critique not only of state schooling for 'Africans', but also of the domination of English in education in the form of the English as a Second Language (ESL) industry - what Heugh calls 'the covert forms of the hegemony of English' (1992). Thus 'subtractive bilingualism' has become synonymous with poor academic performance, low self-esteem, and social marginalisation associated with deficit approaches and language policies that officially replace learners' primary (or home) languages as LOLTs with a target language of higher status after only a few years of schooling. In practice this means that 'African' children have to transition suddenly into English-medium classes, with debilitating consequences (see Macdonald 1990). 'Additive bilingualism', on the other hand, has become a shorthand expression for a language-in-education approach designed to foster advanced bilingual proficiency, cognitive development, and general social empowerment preferably through the use of two LOLTs, one of which has to be the primary or home language of the majority of learners.

\section{1. 'Additive bilingualism': conflating categories}

A feature of the discourse on language-in-education policy and bilingual education in South Africa is the conflation of several dimensions of 'additive' and 'subtractive bilingualism'.

'Additive bilingualism' refers to 
1. the gaining of linguistic competence in individuals (process and outcome): 'By additive bilingualism is meant the gaining of competence in a second language while the first language is maintained' (Luckett 1993)

2. a form of programme or model: "An additive bilingual model is simply one which adds languages to a child's repertoire, instead of subtracting them. In an additive model, therefore, children's home languages are fully acknowledged and utilised throughout education.' (Musker 1993, in Eltic 1997)

3. an educational principle, paradigm or approach: '...additive bilingualism as the core principle of a future policy for language in education.' (Constable \& Musker 1993)

This is an unusually wide range of meanings for a single concept. In the light of the sometime conflation of individual proficiency, programme type (the LOLT/language-as-a-subject [LaS] combination), and educational philosophy, the consensus ${ }^{2}$ on what constitutes a desirable language policy for schools is nothing short of remarkable. Experience with bilingual education internationally has helped South African researchers gain a large measure of clarity in an area (language in education) in which the variables are notoriously difficult to isolate for purposes of research. Nevertheless, a cautionary note is in order. I believe we should be careful not to automatically equate individual language learning outcomes with particular programme types or models. While it is true that bilingual education programmes for speakers of dominated languages (in which the home language is developed as the primary linguistic resource) achieve the best results, it is conceivable that even dual-medium or two-way immersion programmes could fail in under-resourced or overcrowded circumstances (and hence be termed 'subtractive'). If at all, the descriptor 'additive' should be used with caution. We should be clear when we mean LOLT/LaS classroom approaches (e.g. dual medium), and when we mean linguistic and cognitive outcomes in learners. Identifying the one too closely with the other could mean that we ignore evidence that appears to contradict our framework.

\section{2. 'Subtractive bilingualism': uses and problems}

'Subtractive' in the context of bilingual/multilingual education research in South Africa has come to be used in a similarly wide range of ways. Current uses of 'subtractive bilingualism' clearly indicate that the authors/documents are unanimous in their rejection of certain types of approaches and LOLT/LaS policies. Subtractive bilingualism is a state of linguistic or cognitive (under)development in individuals. It also refers to the context or situation in which such (under)development occurs, including language distribution models (LOLT/LaS). And it refers to a particular paradigm or mindset that is usefully termed 'deficit'. Effectively, 'subtractive bilingual programmes' are equated with ex-DET schooling, which is characterised by transitional programmes that switch from learners' main language to the target language (English) after the early years and are generally associated with catastrophic exam results - in short, they are disabling (Heugh 1995). Yet like its 'additive' twin, 'subtractive bilingualism' appears to conflate learner outcomes with programme types and a particular mode of thinking. On closer inspection there appear to be three further problems with the construct, however.

2 Without exception, the surveyed documents understand the minimum requirement for educational success to be $\mathrm{Ll}$ development as the basis for further acquisition of languages and general cogntive and affective growth. 
3.2.1. 'Subtractive bilingualism' does not add up. Current definitions treat 'language' as a monolithic, global cognitive proficiency, instead of as a set of oral and literacy practices within social contexts, overdetermined by relations of power. The question is: what exactly is being lost or subtracted? If a home language of low status is not used as LOLT at school after the first four years, does it necessarily follow that the learner will lose the ability to use her main language in other contexts? Surely Wiley is right in pointing out that ' $[\mathrm{m}]$ ost normal human beings have command of their native languages, regardless of whether they are literate or not' (1996:158). Hence on 'mathematical' grounds alone, 'subtractive' does not add up. ${ }^{3}$

\subsubsection{It reverses cause and effect. A second problem is that 'subtractive bilingualism'} (unintentionally) reverses cause and effect. 'But when subtractive bilingualism occurs, a second language is learned at the expense of the first language, which it gradually replaces. This occurs when the social conditions devalue the child's first language and its associated culture. This form of bilingualism may impede cognitive and social development' (Luckett 1993:47). Along with other similar versions, Luckett's definition implies that a situation or context is defined as 'subtractive' because learners perform poorly in tests and exams. But this is a back-to-front way of defining context. What the definition means is that the effects are 'subtractive', not the context. This use of contexts or situations (when subtractive bilingualism 'occurs') is misleading as it unwittingly 'blames the victim': programmes and models and situations and contexts are named after learners' alleged lack of proficiency in the language of power - a lack that is no fault of the learners'. It is a case of reversing cause and effect.

3.2.3. It is politically insensitive. To attribute cognitive and linguistic outcomes in learners to bilingual programmes is problematic, as it carries the risk of stigmatising certain groups of learners. All educators in South Africa will know what Luckett and others are referring to the real risk of failure of an entire generation of students whose main languages have been replaced as LOLTs after the early years of schooling, and whose proficiency in English is too poor for them to succeed academically. Yet not only is it doubtful that the majority of South Africans are cognitively deficient on account of their schooling; it is politically extremely insensitive to imply it. The political problem of the term 'subtractive bilingualism' is that it risks stigmatising black (particularly African) students, thus influencing educators into assuming that nothing good could come out of ex-DET schooling. It is the ascription of the cognitive and linguistic outcomes (in learners) to bilingual programmes that is problematic.

\subsection{Bilingual education $=2$ LOLTs!}

In the international literature there is general consensus that the term bilingual education, especially in its strong interpretation, entails the use of two LOLTs at some point in the curriculum. 'This definition insists on the use of two languages as media of instruction' with the aim of '[fostering] the child's abilities in both languages' (Liddicoat 1991:14,15). In South

It may be the case, however, that African language-speaking children enrolled in schools where English is the only language used by teachers and most learners, and whose parents insist on interacting in English with their children in the (misguided) belief that it speeds up acquisition of the dominant language, have lost some of their ability to use the home or main language for the reason that it is not reinforced sufficiently in other domains. In such cases the overall language environment or context would indeed be 'subtractive' of children's ability to use the home language/s. Even then, the school in itself would not be the only institution or social domain responsible for this language loss. 
Africa, too, bilingual education has generally come to mean use of two LOLTs. Under apartheid, the term was limited to the dual-medium Afrikaans/English schooling (Malherbe 1977), and excluded the African languages (DoE 1995). Luckett argues strongly in favour of

a strict definition of bilingual education [which] insists that both languages are used as media of instruction at some point in the curriculum; i.e. language learning experience is provided both through learning the languages as a subject and through learning other subjects in the target language. If we are serious about the goals of language equality and full bilingualism, then this definition of bilingual education should be adopted... for the majority of South African pupils, the successful learning of a second language will best be achieved if it is taught both as a subject and as the medium of instruction. $(1993: 47-8)$

In similar vein, the CEPD document (1993) describes an 'additive bilingual/multilingual approach to language in education' as follows: 'Both (all) languages are perceived and used as languages of learning throughout the learner's school career.' The first draft of the DoE's language policy for schools, states quite explicitly that '[a] key feature of a multilingual policy is that it promotes the use of two or more languages throughout schooling' (1995:256). Thus 'bilingual education' implies the use of two LOLTs. This brings us to the meanings and uses of 'additive multilingualism' in recent reports and policy documents.

\section{MULTILINGUAL EDUCATION AND 'ADDITIVE MULTILINGUALISM'}

Clearly, the term 'additive multilingualism' has not fallen from the sky; it consciously builds on its predecessor, 'additive bilingualism' and has often been used in conjunction with it, e.g. 'an additive bilingual/multilingual approach' (CEPD 1993), and 'additive bi- or multilingualism' (Alexander 1996). The historical significance of 'additive multilingualism' is that it consciously and deliberately alludes to the official recognition of multilingualism as a feature of South African society, enacted by the declaration of eleven official languages in the Constitution. In particular, 'multilingualism' celebrates nine indigenous languages (and by implication their speakers or users) as national resources. The use of the term signals the discursive break with the oppression of apartheid-colonial bilingualism, which recognised only English and Afrikaans as official languages, i.e. you were 'bilingual' only if you spoke those two. Multilingualism enshrines the principle of equality between the eleven languages. 'Additive multilingualism' is designed to operationalise the principle in the educational sphere.

Yet in current policy documents there is a degree of vacillation in terminology which hints at some of the contextual constraints under which the policy-making process has had to operate. As Du Toit et al. (1997:6) point out, 'additive multilingualism' in the Language Policy for Schools document (1997a:4) is used interchangeably with 'an additive approach to bilingualism' (ibid:3), which is (mis)quoted as 'an additive approach to multilingualism' in the Curriculum 2005 brochure (DoE 1997b:22). Fortunately, the Language Policy document has a principled position in this regard: 
Whichever route [towards multilingual education] is followed, the underlying principle is to maintain home language(s) while providing access to and the effective acquisition of additional language(s). (3)

This principle is operationalised through a language policy that takes into account a school's admissions policy, languages of learning and teaching, languages as subjects, and various norms and standards. Most significant is the learner's right (in practice the parent/guardian) to choice with regard to LOLT, and the injunction that 'Schools shall provide for more than one language of teaching where the need arises' (DoE 1997b:23). The 'need arises' where sufficient numbers of learners request a particular LOLT, subject to reasonable practicality. As Greenstein points out, the 'dense legal formulation of the document' (1997) is the result of a concession to conservative Afrikaners who have resisted the introduction of English as a second LOLT (and the enrolment of black learners) in Potgietersrus and elsewhere. As a result of this political compromise,

it seems the matter will be resolved by extending the definition of additive multilingual education to include situations where single-medium schools offer high-quality subject teaching in the relevant additional languages. (Alexander 1996:7)

This minimalist interpretation of 'additive multilingualism' to effectively mean 'mother tongue education' has resulted in a degree of uncertainty in current policy documents. Du Toit et al., for instance, take issue with 'the apparent lip-service given to an additive bilingual/multilingual model of language-in-education' (1997:5) in Curriculum 2005. The authors are concerned that the reference to language of learning (in the singular) and the absence of any affirmation of 'the cognitive role of the primary language' appear to signal the government's lack of commitment to overcoming 'the deficit model of the past' (6). Quite clearly, the authors are implying that since 'bilingual education' is generally taken to mean the use of two languages of learning and teaching at some point in the instructional process, 'multilingual education' implies the use of at least two, and possibly three or more LOLTs. It is quite likely that in addition to the political constraints mentioned above, budgetary constraints on employing and training more (bi- and trilingual) teachers and producing appropriate resources for education for multilingualism have played a role in accepting singlemedium schools within the definition of 'additive multilingual education'. The net effect of these constraints is that 'multilingual education' and 'additive multilingualism' have come to mean a lot less than their names suggest.

\section{MINDING OUR LANGUAGE}

The concepts we use not only encode our thoughts, they also shape the paradigms and practices we live by. It remains important therefore to synchronise our terms with what we actually want them to mean. In this article it has been argued that current language-ineducation policy documents use terms that either need to be defined more carefully, or that are unsuitable altogether.

Terms that no longer appear useful to me are 'subtractive bilingualism', 'additive bilingualism', and 'additive multilingualism'. This is because they conflate a number of different dimensions, unwittingly stigmatise the victims/survivors of a discriminatory system, 
and in the case of the latter are open to misinterpretation. 'Subtractive/ transitional bilingualism' should be dropped because, even on its own terms, it conflates cognitive and linguistic outcomes in learners with a programme type.

The most important of the older concepts that should be reintroduced is bilingual education, meaning the use of two LOLTs in the educational process. Dual-medium education should be the preferred ('strong') form of bilingual education, with parallel-medium education ( $2 \mathrm{x}$ single-medium education in the same school, with plenty of opportunities for contact across language lines) an interim solution until teachers have been enabled to teach through the medium of two LOLTs. It may be possible to rehabilitate the concept of mother-tongue education $^{4}$; if not, its equivalents of primary languages or main languages or home language/s education should be punted. The term developmental could fittingly replace additive to describe approaches and programmes designed to empower learners cognitively, linguistically, affectively, socially, culturally. Developmental has the advantage of being a more holistic term, thereby referring to more than simply the language dimension (which is never in isolation from other developmental aspects such as literacy practices) of learning in a particular programme design. It contrasts with a deficit approach (in place of 'subtractive'), which draws attention to the theoretical assumptions underlying disabling learning approaches and programmes, rather than to the outcomes in learners themselves. While education for multilingualism is acceptable, the concept of multilingual education should perhaps be put on hold until other, older concepts have been re-established and given meaning. Language-ineducation policy in South Africa will, in addition to new concepts, also require older terms for the task ahead.

\section{A CHALLENGE FOR AFRICAN LANGUAGES}

Changing our terms or reimbuing old ones with new meanings will not in itself change language-in-education policies. Other measures are needed to give effect to the new language policy in ways that are enabling of all learners in South Africa - particularly speakers of African languages, the survivors of colonial-apartheid 'bilingualism'.

A proposal for making an African language a compulsory subject comes from Granville et al. (1997), and is a direct challenge to the new language policy which has come out strongly against prescription with regard to both LOLT and language as a subject (LaS). Granville et al. propose 'a strong language-as-subject route to a multilingual policy' (1997:14) in terms of which '[a]ll students must learn at least one African language as subject throughout the years of compulsory schooling' [ibid.). The authors allude to the fact that what sparked the Soweto revolt in $\mathbf{1 9 7 6}$ was the enforced extension of Afrikaans as a LOLT, not its status as a language subject. They note the 'sensitivities that the LANGTAG (Language Plan Task Group) document was obviously protecting' in stopping short of making an African language compulsory, but make a crucial distinction:

there is a huge difference between a dominant language (such as Afrikaans) being imposed upon a marginalised community, and a marginalised language, such as an African language, being imposed on a dominant community. We cannot make a 
simple comparison between the two scenarios without considering i) the power and resource differences between the communities and the languages being compared in ii) the overriding benefits of the 'imposition' that we propose (Joseph \& Ramani, 1996: p 10) $(1997: 17)$

Benefits would include, at the very least, an adequate level of bilingual competence (ibid:11) for learners previously denied the chance to learn an African language. The authors' reasoning shows an acute sense of the power/status issues in language-in-education in substantiating their proposal:

We think it ironic that African languages which once suffered underdevelopment through Afrikaans and English domination, should now suffer a second round of underdevelopment on the noble but mistaken sensitivities over perpetuating our legacy of 'imposition'... We are arguing that, in South Africa, this additional language must be an African language, but with freedom to choose among any of the African languages. (1997:17)

This would have major implications for the training and placement of teachers, for curriculum development, and for learning materials. At the same time, it is a more realistic short-term scenario than the extension of the use of African language as LOLTs throughout schooling, which the authors see as a long-term goal. 'Going for an African language as LOLT policy as though it were practicable now, could prove to be a recipe for its failure, and for the (unintended) continuation of dominance of English as LOLT' (ibid:18).

\section{AN OPENING}

There is general consensus that a key to the promotion of multilingualism in schools is the systematic elaboration, standardisation and use of the African languages in education and society. If we agree with Granville et al (1997) that the use of African languages as LOLTs throughout schooling is not feasible overnight (although a desirable longer term scenario), a case can nevertheless be made for extending the African languages as LOLTs in a staggered or phased way that runs parallel to the extension of Curriculum 2005, possibly in a number of pilot or demonstration schools across the provinces. A developmental concept is appropriate here: with each successive Grade that is ' $\mathrm{OBE}(\mathrm{Y})$-ed', dual-medium or parallel medium programmes could be implemented. This would of course require the training of teachers, the production of teaching and learning material in the African languages (or in two languages) ${ }^{5}$, and language awareness campaigns on different levels (cf LANGTAG) to conscientise parents and teachers about the need for such an initiative. Various models of bilingual education could be trialled, depending on contextual factors; and innovative concepts such as Gough's suggestion of 'formative' and 'supportive mediums' (1996) deserve to be explored. For all the messiness of its indecently-hasty implementation, Curriculum 2005 thus offers the chance to dovetail with the new Language Policy for schools in ways consistent with the argumentation in this article.

See the chapter by Kate McCallum in Heugh et al (eds., 1995), in which she describes various options for bilingual textbooks. 
If we are serious about education for multilingualism, the phased introduction and finalisation of the new curriculum over the next seven years should go hand in hand with a systematic exploration of bilingual education. The point is that current policies should work together in order to operationalise the concepts that we would want (our children) to live by.

\section{REFERENCES}

ALEXANDER, N. 1996. Languages of learning and teaching in South Africa. Recent debates and developments. Unpublished paper.

ALEXANDER, N. 1998. Personal communication, January.

BAKER, C. 1993. Foundations of bilingual education and bilingualism. Clevedon, Avon: Multilingual Matters.

Centre for Education Policy Development (CEPD) Language Policy in Education Working Group. 1993. Language Policy in Education. Draft report, June.

CONSTABLE, P AND P MUSKER. 1993. Language in education - policy considerations. Unpublished paper, May.

Department of Education. 1995. Towards a language policy in education. Discussion document.

Department of Education. 1997a. Language in education policy. 14 July. Pretoria: DoE.

Department of Education. 1997b. Curriculum 2005. Brochure. Pretoria: DoE.

DU TOIT, C, P CONSTABLE AND V KENYON. 1997. Curriculum 2005 discussion document. Saala Communique, June.

GOUGH, D. 1996. Primary and secondary models in orality and literacy. In Language and literacies. Proceedings of the 16th Annual Conference of the Southern African Applied Linguistics Association.

GRANVILLE, S, H JANKS AND M JOSEPH (et al). 1997. English with or without g(u)ilt: A position paper on language in education policy for South Africa. Unpublished paper.

GREENSTEIN, R. 1997. Curriculum 2005. In Wits EPU Quarterly Review of Education and Training in South Africa, Vol. 4, No. 4.

HEUGH, K. 1992. Effecting equality: A proposal for multilingual classrooms. Unpublished paper. 
HEUGH, K. 1995. Disabling and enabling: implications of language policy trends in South Africa. In Mesthrie, R. (ed.) Language and Social History. Cape Town \& Johannesburg: David Philip.

LAMBERT, W.E. 1983. Deciding on languages of instruction: psychological and social considerations. In Husén, T. \& Opper, S. (eds.). Multicultural and Multilingual Education in Immigrant Countries. Oxford: Pergamon Press.

Language Plan Task Group (LANGTAG). 1996. Towards a national language plan for South Africa. Pretoria: Department of Arts, Culture, Science and Technology.

LIDDICOAT, A. 1991. Bilingualism: an introduction. In Liddicoat, A. (ed.). Bilingualism and Bilingual Education. Melbourne: National Languages Institute of Australia.

LUCKETT, K. 1993. "National Additive Bilingualism": towards the formulation of a language plan for South African schools'. SAJALS, Vol.2 No.1.

MACDONALD, C.A. 1990. Crossing the threshold into standard three in black education. Pretoria: HSRC.

MALHERBE, E.G. 1977. Education in South Africa Vol.2 (1923-75). Cape Town: Juta.

MCCALLUM, K. 1995. Educational publishing: a practical look at language policies. In Heugh, K. et al. (eds.). Multilingual Education for South Africa. Johannesburg: Heinemann.

MUSKER, P. 1997. Language for success. In ELTIC. Multilingual learning. Cape Town: Maskew Miller Longman.

PHILLIPSON, R. 1988. Linguicism: Structures and ideologies in linguistic imperialism. In Skutnabb-Kangas, T. \& Cummins, J. (eds.).

PLÜDDEMANN, P. 1996. Response to multilingualism: language support in a Western Cape primary school. Unpublished MPhil dissertation, University of the Western Cape.

RAMIREZ, JD, SD YUEN, DR RAMEY. 1991. Final report: longitudinal study of structured english immersion strategy, early-exit and late-exit transitional bilingual education programs for language-minority children. Executive summary. San Mateo: Aguirre International.

SKUTNABB-KANGAS, T. 1988. Multilingualism and the education of minority children. In Skutnabb-Kangas, T. \& Cummins, J. (eds.). Minority education: from shame to struggle. Clevedon: Multilingual Matters. 
THOMAS, WP AND VP COLLIER. 1997. School effectiveness for language minority students. Summary of report for National Clearinghouse for Bilingual Education.

TOSI, A. 1990. Bilingual education. Annual review of applied linguistics, Vol.10. 